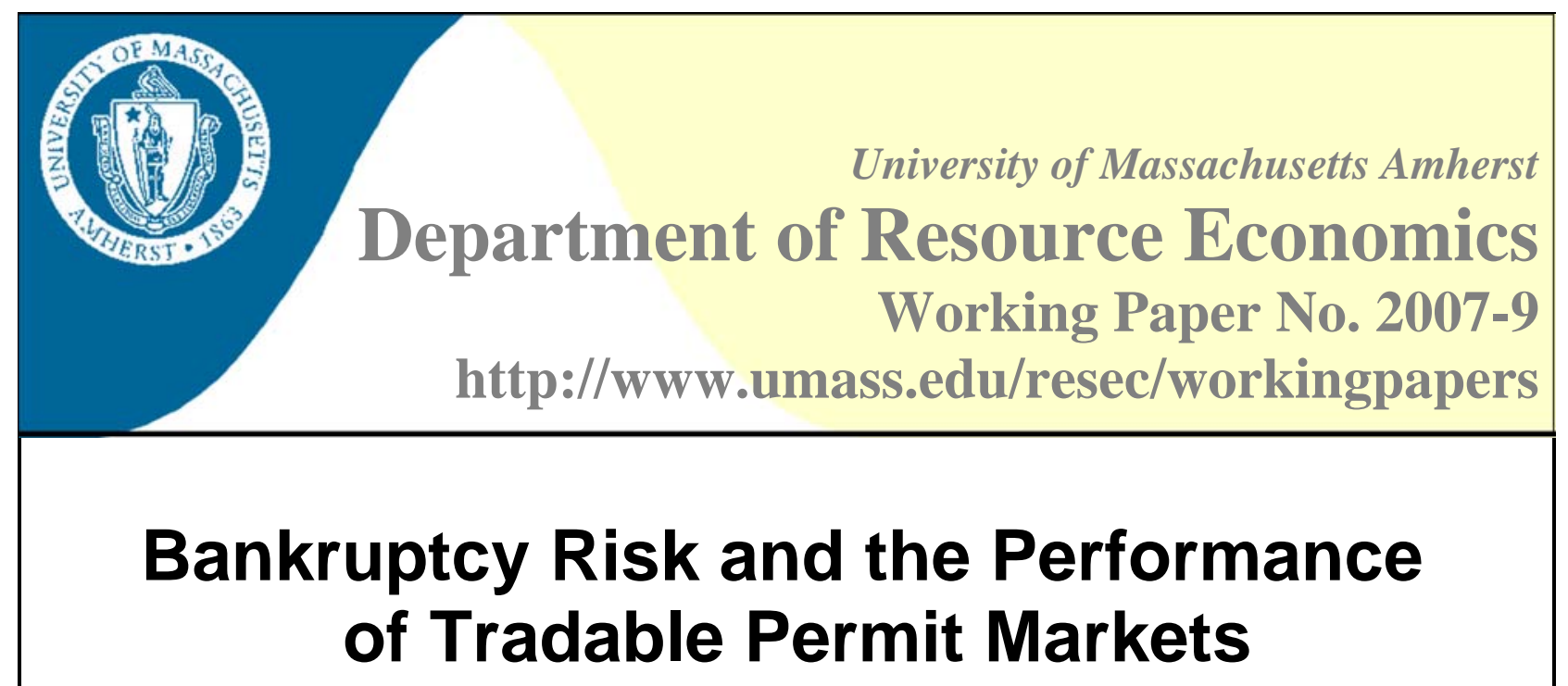

John K. Stranlund ${ }^{1}$ and Wei Zhang ${ }^{2}$

\begin{abstract}
:
We study the impact of bankruptcy risk on markets for tradable environmental and natural resource permits. We find that firms that risk bankruptcy demand more permits than if they were financially secure. Consequently, bankruptcy risk in a competitive market for tradable property rights causes an inefficient distribution of individual choices among regulated firms. Moreover, the equilibrium distribution of permits is not independent of the initial distribution of permits. In fact, the inefficiency that is associated with bankruptcy risk is mitigated if financially insecure firms are given a larger share of the initial allocation of permits.
\end{abstract}

Keywords: bankruptcy, tradable permits, permit markets

JEL Classification: L51, Q28, Q58

\footnotetext{
${ }^{1}$ John K. Stranlund, Department of Resource Economics

University of Massachusetts, 214 Stockbridge Hall

80 Campus Center Way, Amherst, MA 01003

E: stranlund@resecon.umass.edu P: 413-545-6328 F: 413-545-5853

${ }^{2}$ Wei Zhang, Department of Resource Economics

University of Massachusetts, Stockbridge Hall

80 Campus Center Way, Amherst, MA 01003

E: wzhang@resecon.umass.edu F: 413-545-5853
} 
August 2007

\title{
Bankruptcy Risk and the Performance of Tradable Permit Markets
}

\author{
John K. Stranlund* \\ Department of Resource Economics \\ University of Massachusetts, Amherst \\ Wei Zhang \\ Department of Resource Economics \\ University of Massachusetts, Amherst
}

Acknowledgements: Support for this work was provided by the Cooperative State Research Extension, Education Service, U. S. Department of Agriculture, Massachusetts Agricultural

Experiment Station, and the Department of Resource Economics under Project No. MAS00871. We gratefully acknowledge the comments and suggestions of L. Joe Moffitt.

\footnotetext{
* Correspondence to John K. Stranlund, Department of Resource Economics, 214 Stockbridge Hall, 80 Campus Center Way, University of Massachusetts-Amherst, Amherst, MA 01003, USA. Phone: (413)545-6328, Fax: (413)545-5853, E-mail: stranlund@resecon.umass.edu.
} 


\section{Bankruptcy Risk and the Performance of Tradable Permit Markets}

Abstract: We study the impact of bankruptcy risk on markets for tradable environmental and natural resource permits. We find that firms that risk bankruptcy demand more permits than if they were financially secure. Consequently, bankruptcy risk in a competitive market for tradable property rights causes an inefficient distribution of individual choices among regulated firms. Moreover, the equilibrium distribution of permits is not independent of the initial distribution of permits. In fact, the inefficiency that is associated with bankruptcy risk is mitigated if financially insecure firms are given a larger share of the initial allocation of permits.

Keywords: Bankruptcy, Tradable permits, Permit markets

JEL Codes: L51, Q28, Q58

\section{Introduction}

Market-based polices have become an accepted approach to regulating environmental and natural resource externalities. Tradable permit policies have been designed and implemented to manage air and water pollution, fish harvests, water use, and land use. ${ }^{1}$ The fundamental value of competitive permit markets is that they produce the cost-efficient allocation of individual rights to a resource under a fixed aggregate cap on these rights. Moreover, the equilibrium distribution of permits is independent of their initial allocation, giving regulators the freedom to use the initial allocation of permits to pursue other objectives, such as those arising from equity concerns or the exercise of political power, without upsetting the cost-effectiveness property. (Montgomery 1972).

Of course, the performance of tradable permit schemes depends critically on the assumption of competitive permit trading. Hahn (1984) was the first to demonstrate that market power in an emissions trading scheme would generally lead to an inefficient distribution of emissions control responsibilities, and that the initial distribution of permits would impact the

\footnotetext{
${ }^{1}$ See Teitenberg (2003) for a survey of the design and performance of tradable permit programs for each of these applications.
} 
equilibrium distribution of emission control. ${ }^{2}$ Similarly, Stavins (1995) demonstrated that variable transaction costs associated with trading emissions permits would lead to an inefficient distribution of emissions control among regulated firms, and that this distribution of control might depend on the initial allocation of permits. ${ }^{3}$

In this paper we examine how tradable permit markets perform in the presence of financially distressed firms, and show that it is yet another potential source of allocative inefficiency. With the continuing application of market-based policies into new environmental and natural resource settings, it is certain that regulators will confront, or have already confronted, situations involving financially distressed firms. Thus, knowledge of how the financial health of regulated firms can impact the performance of market-based policies is an important consideration in the design and evaluation of these policies.

We are certainly not the first to demonstrate that the financial health of firms can impact the performance of markets. For example, Brander and Lewis (1986) show that the Nash equilibrium of a model of Cournot duopolists is affected by the firms' debt levels. We are also not the first to demonstrate that bankruptcy risk may impact regulatory designs, including environmental and natural resource policies. Spiegel and Spulber (1994) investigate the interactions between the investment and financial decisions of firms and a regulator's control of their output price. Larson (1996) analyzes the impact of bankruptcy risk on firms' choices when their income is uncertain and they operate under a strict liability rule. Damania (2000) explores

\footnotetext{
2 The literature on market power in markets for tradable property rights is now quite extensive. See Tietenberg (2006) for a thorough review of the part of this literature that focuses on emissions trading.

${ }^{3}$ Also see Montero (1997). A number of authors have considered how transaction costs have affected the performance of actual trading programs. Cason and Gangadharan (2003) provide a review of this literature. The primary motivation of their paper is to use laboratory markets to test the impacts of transaction costs on tradable permit markets. Their results generally support the conclusions of Stavins (1995).
} 
the link between pollution taxes and the financial and output decisions of firms in an oligopolistic industry, and shows that there are circumstances under which highly leveraged firms respond to pollution taxes by increasing their emissions. In a more recent work, Damania and Bulte (2005) relate the harvest decisions of firms in a fishery to the financial structure of the industry and regulatory control. Contrary to predictions about the decisions of firms in the absence of bankruptcy risk, they demonstrate that there are circumstances under which the risk of bankruptcy will cause firms to increase their harvests and violations of harvest quotas as noncompliance penalties are increased or harvest quotas are reduced.

To our knowledge our work is the first to examine how the risk of bankruptcy affects the performance of tradable property rights regulations. We demonstrate that firms under these regulations that face a positive risk of bankruptcy will demand more permits than they would if they did not risk bankruptcy. Consequently, the decisions of financially distressed firms will cause the equilibrium distribution of permits to differ from the efficient distribution of permits. Moreover, the equilibrium distribution of permits and the allocative loss produced by financially distressed firms will depend on the initial distribution of permits—a larger initial allocation of permits to distressed firms will reduce their risk of bankruptcy and their demands for permits. Thus, there are welfare consequences of the initial distribution of permits that are not present when permit markets do not include financially distressed firms. In fact, distributing a greater number of permits to distressed firms reduces the inefficiency associated with bankruptcy risk.

The rest of the paper is organized as follows: In the next section we lay out a model of a value-maximizing firm that operates under a tradable permit program and that may risk insolvency. In section 3 we investigate the effect of financial distress on a firm's demand for permits and demonstrate that bankruptcy risk upsets the allocative-efficiency property that is 
normally associated with competitive permit trading. In section 4 we demonstrate how bankruptcy risk affects permit markets, particularly the efficiency consequences of the initial distribution of emission permits. We conclude in section 5.

\section{A Model of a Value-Maximizing Firm under a Market-Based Regulation}

Consider an industry whose aggregate output is limited by a tradable output permit policy. Output in our model may be interpreted as emissions of a pollutant, fish harvests, water use, or units of land development. We assume that the industry contains a fixed number of heterogeneous firms, and the manager of each firm in the industry seeks to maximize the value of the firm. A firm's output, $q$, generates profit, $\pi(q)(1+z)$, where $z$ is a continuous random variable that is independently, but not identically, distributed in the industry. This random variable captures the effects of uncertainty on the firm's profit, such as the effects of random shifts in the demand for its output or random changes in its factor prices. The probability density function of $z$ is $g(z)$ with support $[\underline{z}, \bar{z}]$. The expectation of $z$ is zero so the firm's expected profit is simply $\pi(q)$. The value of $z$ is revealed only after all production and permit market decisions have been made.

We assume that the firm's expected profit is strictly concave in its output. In the absence of regulatory inducement to control its output, a value-maximizing firm will choose its output to maximize its expected profit. We denote this level of output as $q^{m}$, which is the solution to $\pi^{\prime}(q)=0$. It will become obvious in the next section, particularly in footnote 4 , that the way we've modeled a firm's uncertainty implies that its unregulated level of output is $q^{m}$ whether it risks bankruptcy or not. The implementation of a tradable permit scheme generates a price for output permits that motivates the firm to reduce its output below $q^{m}$. We assume that $\pi(q)>0$ 
for $q \in\left[0, q^{m}\right]$; that is, the firm's expected profit is strictly greater than zero in the relevant range of output.

The firm receives an initial endowment of permits $l^{0}$. Each permit gives the firm the right to produce one unit of output. Assume that enforcement of the tradable permit program is sufficient to induce full compliance, so that the firm holds the same number of output permits as its level of output. The market for permits is perfectly competitive so that trade establishes a constant price per permit $p$, which each firm takes as given. The firm’s expenditure or revenue from permit transactions is $p\left(q-l^{0}\right)$.

Like Damania and Bulte (2005) we focus on the short run in which firms have determined their capital structure. Thus, the financial structure of a firm is summarized by its fixed equity, $A$, and its fixed debt obligation, $D$. Given a realization of $z$, the value of the firm is

$$
v(q, z)=\pi(q)(1+z)-p\left(q-l^{0}\right)-D+A .
$$

If $v(q, z)$ turns out to be negative, the firm's losses exceed its equity. It then declares bankruptcy and uses its equity to partially pay off its creditors. Apart from losing its equity, $A$, there are no other costs of declaring bankruptcy. If $v(q, z)$ turns out to be greater than zero, the firm remains solvent. Note that the firm is willing to tolerate an operating loss if it does not exceed its equity. Define a critical breakeven state, $\hat{z}$, in which the firm's equity is just sufficient for it to avoid bankruptcy:

$$
\hat{z}=z \mid v(e, \hat{z})=\pi(q)(1+\hat{z})-p\left(q-l^{0}\right)-D+A=0 .
$$

Solving for $\hat{z}$ yields

$$
\hat{z}=\frac{p\left(q-l^{0}\right)+D-A}{\pi(q)}-1 .
$$


If the realized value of $z$ is greater than $\hat{z}$, the firm remains solvent, but it is insolvent if the realized value of $z$ is less than $\hat{z}$. The probability that the firm avoids bankruptcy is the probability that $z \geq \hat{z}$; that is, $\int_{\hat{z}}^{\bar{z}} g(z) d z$. Note that if $\hat{z} \leq \underline{z}$, the firm does not risk bankruptcy. At the other end of the range of $z, \hat{z} \geq \bar{z}$ implies that the firm will definitely be insolvent. Obviously, in this case the firm will not even bother to begin production. In the more interesting cases in which $\hat{z} \in(\underline{z}, \bar{z})$, the probabilities that the firm will be solvent or insolvent are both strictly between one and zero. Moreover, the probability of bankruptcy increases with $\hat{z}$.

From [3], the first derivatives of $\hat{z}$, for $\hat{z} \in(\underline{z}, \bar{z})$, are:

$$
\begin{aligned}
& \hat{\mathrm{z}}_{A}=\frac{-1}{\pi(q)}<0, \hat{\mathrm{z}}_{l^{0}}=\frac{-p}{\pi(q)}<0, \hat{\mathrm{z}}_{D}=\frac{1}{\pi(q)}>0, \\
& \hat{\mathrm{z}}_{p}=\frac{\left(q-l^{0}\right)}{\pi(q)} \text {, and } \hat{\mathrm{z}}_{q}=\frac{p-\pi^{\prime}(q)(1+\hat{z})}{\pi(q)} .
\end{aligned}
$$

(Throughout, derivatives are indicated by subscripts in the usual fashion). Recalling that $\pi(q)>0$, note that an increase in the firm's equity reduces the breakeven value of $z$ and the probability that it will be forced to declare bankruptcy. Similarly, since the initial allocation of permits is an additional asset, an increase in the firm's initial allocation of permits reduces $\hat{z}$ and the probability that it will be insolvent. Of course, an increase in the firm's debt payment, $D$, increases $\hat{z}$ and the probability the firm will be insolvent. The effect of a change in the price of permits on the probability of insolvency depends on whether the firm is a net buyer or net seller of permits. If the firm sells permits, an increase in the price of permits increases the value of the firm and reduces the probability that it will be bankrupt. If the firm buys permits, a price increase increases the likelihood the firm will be insolvent. Finally, the effect of the firm's level of output on the likelihood of insolvency depends on the relationship between the permit price and the 
firm's marginal profit evaluated at $\hat{z}$. In general the sign of $\hat{z}_{q}$ is indeterminate, but we will show later that it is positive when the firm chooses its production optimally.

The manager of the firm is risk neutral and chooses the firm's output to maximize the expected value of the firm. Denote the expectation of $v(q, z)$ as $V(q, z)$. Therefore:

$$
V(q, z)=\int_{\underline{z}}^{\hat{z}}(-A) g(z) d z+\int_{\hat{z}}^{\bar{z}}\left[\pi(q)(1+z)-p\left(q-l^{0}\right)-D\right] g(z) d z .
$$

Throughout we assume that $V(q, z)$ is strictly concave in $q$ for every feasible value of $z$, and that the firm optimally chooses a positive level of output. Note that the firm only considers states of insolvency because it risks losing its equity. That the loss in bankrupt states is independent of the firm's output has important consequences for the firm's choice of output.

\section{Bankruptcy Risk and a Firm's Demand for Permits}

In the standard demonstration of the ability of a competitive permit market to distribute individual production choices efficiently, firms maximize expected profit without fearing the possibility of bankruptcy. In our model, if a firm is immune to bankruptcy, then $\hat{z} \leq \underline{z}$ and [5] reduces to $V(q)=\pi(q)-p\left(q-l^{0}\right)-D$. This indicates clearly that the firm takes its equity into account only when it risks losing it. When there is no such risk, the firm chooses its output so that $p=\pi^{\prime}(q)$, which is the familiar condition that a firm chooses its output and permit demand to equate its marginal expected profit to the going permit price. If no firm under a tradable permit program faces bankruptcy, their production choices equate their expected marginal profits. This, of course, forms the set of necessary conditions for maximizing expected industry profit, given that aggregate output is limited to some exogenous standard. 
Matters are very different if some firms risk bankruptcy. Given our assumptions that [5] is strictly concave in a firm's output and that the firm chooses positive output, the following first order condition is both necessary and sufficient to uniquely determine its optimal choice of output:

$$
V_{q}=\int_{\hat{z}}^{\bar{z}}\left[\pi^{\prime}(q)(1+z)-p\right] g(z) d z-\hat{z}_{e} g(\hat{z})\left[\pi(q)(1+\hat{z})-p\left(q-l^{0}\right)-D+A\right]=0 .
$$

Using the definition of $\hat{z}$ provided by [2], the first order condition simplifies to

$$
V_{q}=\int_{\hat{z}}^{\bar{z}}\left[\pi^{\prime}(q)(1+z)-p\right] g(z) d z=0 .
$$

Rearranging [6] gives us

$$
p=\pi^{\prime}(q)[1+E(z \mid z>\hat{z})],
$$

where

$$
E(z \mid z>\hat{z})=\int_{\hat{z}}^{\bar{z}} z g(z) d z / \int_{\hat{z}}^{\bar{z}} g(z) d z
$$

is the expectation of $z$ ( $E$ is the expectation operator) when its distribution is truncated on the left at $\hat{z} .{ }^{4}$ Therefore, $E(z \mid z>\hat{z})$ is the expectation of $z$ conditional on the firm being solvent. ${ }^{5}$ In fact, the right hand side of [7] is the firm's expected marginal profit over states in which it avoids bankruptcy. Why does the firm ignore states in which it is bankrupt when choosing its output? Because its loss in bankrupt states is its constant level of equity, $A$, which does not depend on its output. The fixed limit on the firm's bankruptcy liability causes it to choose its output to optimize over only the states in which it will be solvent.

\footnotetext{
${ }^{4}$ A financially distressed firm's choice of output in an unregulated setting is determined from [7] by setting $p=0$. Doing so yields $q^{m}$, the solution to $\pi^{\prime}(q)=0$. This is the same unregulated level of output that the firm would choose if it did not risk bankruptcy. Other forms of profit uncertainty may not produce this result.

${ }^{5}$ One should be careful to not interpret $p=\pi^{\prime}(q)[1+E(z \mid z>\hat{z})]$ as the inverse permit demand function for a financially distressed firm, because the permit price $p$ appears in $E(z \mid z>\hat{z})$.
} 
The presence of $E(z \mid z>\hat{z})$ in [7] is an adjustment of the firm's choice of output that reflects its risk of bankruptcy. This term disappears when the risk of bankruptcy is zero. That is, when $\hat{z} \leq \underline{z}$, [8] reduces to $E(z)=0$, because the distribution of $z$ is no longer truncated, and [7] reduces to $p=\pi^{\prime}(q)$. Moreover, since $\int_{\hat{z}}^{\bar{z}} z g(z) d z>\int_{\underline{z}}^{\bar{z}} z g(z) d z=0$ when $\hat{z} \in(\underline{z}, \bar{z}), E(z \mid z>\hat{z})$ is strictly positive when the firm risks bankruptcy. This implies that a financially distressed firm will choose its output so that $p>\pi^{\prime}(q)$, which implies further that, given the permit price, its output will be higher than if it did not risk bankruptcy. ${ }^{6}$

The fact that a financially insecure firm does not equate its expected marginal profit to the price of output permits leads directly to one of our main results about the impact of financial insecurity on the performance of competitive permit trading. That is, a tradable permit program that contains financially insecure firms will fail to distribute individual output in the way that maximizes expected industry profit. Accomplishing this objective requires that all firms’ production choices equate their individual expected marginal profits. However, firms that risk bankruptcy choose output so that their expected marginal profits are lower than the going permit price, while those firms that do not risk bankruptcy choose their output to equate their expected marginal profit to the permit price. Moreover, expected marginal profits among financially distressed firms will likely differ, because the values of $\hat{z}$ will vary across these firms, and the densities $g(z)$ may vary as well. Since, the permit market will not equate the firms' expected marginal profits, expected industry profit will not be maximized. Thus, the main reason for

\footnotetext{
${ }^{6}$ Somewhat paradoxically, a firm that risks bankruptcy chooses its output in a way that increases the likelihood that it will turn out to be insolvent. In the absence of bankruptcy risk the firm chooses output so that $p=\pi^{\prime}(q)$ to maximize its expected profit minus the value of its permit transactions. The fact that a financially distressed firm chooses higher output implies that its expected profit less the value of its permit trades is lower and, consequently, the probability that it will be insolvent is higher.
} 
implementing permit trading programs does not hold in situations involving financially distressed firms.

Moreover, the distribution of individual output choices will not be independent of the initial allocation of permits, because financially distressed firms' demands for permits will depend on their permit allocations. To see how, obtain the comparative static $\partial q / \partial l^{0}=-V_{q l^{0}} / V_{q q}$ in the usual manner. Since $V_{q q}<0$ by assumption, the sign of $\partial q / \partial l^{0}$ is equal to the sign of $V_{q l^{0}}$. Differentiate [6] with respect to $l^{0}$ and substitute $\hat{z}_{l^{0}}$ from [4] into the result to obtain $V_{q l^{0}}=(p / \pi(q))\left(\pi^{\prime}(q)(1+\hat{z})-p\right) g(\hat{z})$. To sign this, first note that $\hat{z}<E(z \mid z>\hat{z})$; that is, $\hat{z}$ is less than the expectation of $z$ when its distribution is truncated on the left at $\hat{z}$. Furthermore, since $\pi^{\prime}(q)[1+E(z \mid z>\hat{z})]-p=0$ from [6], $\hat{z}<E(z \mid z>\hat{z})$ implies $\pi^{\prime}(q)(1+\hat{z})-p<0$. This, in turn, implies $V_{q l^{0}}<0$. Therefore, $\partial q / \partial l^{0}<0$, indicating that a financially distressed firm's output is decreasing in its initial allocation of permits. Intuitively, an increase in a firm's initial allocation of permits increases the value of the firm, all else equal. Since this then reduces the risk of bankruptcy of a financially distressed firm, it will choose its output so that the gap between the permit price and $\pi^{\prime}(q)$ is reduced. This results in lower output for a given permit price. In sum, a higher allocation of permits to a financially distressed firm reduces its bankruptcy risk and causes it to choose lower output.

To complete this section, let us determine the effect of a change in the permit price on a financially distressed firm's output. As above, the comparative static $\partial q / \partial p=-V_{q p} / V_{q q}$ has the same sign as $V_{q p}$. From [6] and $\hat{z}_{p}$ from [4] obtain 


$$
V_{q p}=-\int_{\hat{z}}^{\bar{z}} g(z) d z-\frac{q-l^{0}}{\pi(q)}\left[\pi^{\prime}(q)(1+\hat{z})-p\right] g(\hat{z}) .
$$

Note that the first term of $V_{q p}$ is negative. However, recall that $\pi^{\prime}(q)(1+\hat{z})-p<0$ so the sign of the second term of $V_{q p}$ depends on whether the firm is a net buyer or seller of permits. If the firm sells permits $\left(q<l^{0}\right), V_{q p}$ and $\partial q / \partial p$ are both negative. Thus, if the firm sells permits its demand for permits is decreasing in the permit price. However, if the firm buys permits $\left(q>l^{0}\right)$, the sign of $V_{q p}$ is indeterminate because its second term is positive. Note that it is possible that the permit demand function for a firm that simultaneously risks bankruptcy and optimally chooses to buy permits may be upward sloping. As odd as this result appears, it is consistent with a result of Damania and Bulte (2005) who found that an increase in regulatory stringency to induce more conservative harvests in a fishery can lead to less conservative choices by firms that risk bankruptcy. Increased regulatory stringency in our model means that the aggregate cap on output is reduced and fewer permits are issued. Under most circumstances we would expect this to increase the price of permits and lead all firms to reduce their output. However, a financially distressed firm that is a net buyer of permits may react to the reduced cap on aggregate output and increased permit price by increasing its output.

\section{The Initial Allocation of Permits and the Market Effects of Bankruptcy Risk}

In this section we examine the market effects of significant bankruptcy risk, particularly the role the initial allocation of permits plays in determining market outcomes and the allocative efficiency of competitive permit trading. We focus on the initial permit allocation for two reasons. First, increasing the initial supply of permits to financially distressed firms reduces their risk of bankruptcy, everything else equal. Therefore, we can trace out the effects of varying 
bankruptcy risk on permit markets by varying the initial allocation of permits. ${ }^{7}$ Second, in contrast to the conventional wisdom that the initial permit allocation does not affect the performance of competitive permit trading, we've just demonstrated that the initial permit allocation will certainly impact permit markets when some firms risk bankruptcy. Hence, the initial allocation has efficiency consequences that cannot be ignored.

In this section we simplify the analysis by assuming that a permit trading program contains just two types of firms. Type 1 firms do not risk bankruptcy while type 2 firms do. There are $n_{i}$ identical firms of type $i=1,2$. Let $l_{i}^{0}, q_{i}$, and $\pi_{i}$ denote the initial allocation of permits, output, and expected profit function for each type $i$ firm. In equilibrium the output of a type 1 firm is $q_{1}(p)$, the implicit solution of $p=\pi_{1}^{\prime}\left(q_{1}\right)$, which, of course, is independent of their initial allocation of permits because they do not risk bankruptcy. It is straightforward to show that $q_{1}(p)$ is monotonically decreasing in $p .{ }^{8}$ The output of a type 2 firm is $q_{2}\left(p, l_{2}^{0}\right)$, the characteristics of which we explored in the previous section.

With an aggregate supply of permits equal to $L$, the permit market clears if and only if $n_{1} q_{1}(p)+n_{2} q_{2}\left(p, l_{2}^{0}\right)=L$. This equilibrium condition implicitly defines the equilibrium price of permits, $p\left(L, l_{2}^{0}\right)$, as a function of the total supply of permits and the allocation to the financially distressed firms. Differentiate the identity $n_{1} q_{1}\left(p\left(L, l_{2}^{0}\right)\right)+n_{2} q_{2}\left(p\left(L, l_{2}^{0}\right), l_{2}^{0}\right) \equiv L$ with respect to $l_{2}^{0}$ and rearrange the result to obtain the effect of the allocation of permits to the firms that risk bankruptcy on the equilibrium permit price:

\footnotetext{
${ }^{7}$ We could accomplish the same thing with direct financial subsidies to increase financially insecure firms' equity or to reduce their debt obligations. None of our qualitative results would change if the government pursued these alternatives instead of changing the firms' initial permit allocations.

${ }^{8}$ From $p-\pi_{1}^{\prime}\left(q_{1}\right)=0$ obtain $d q_{1} / d p=1 / \pi_{1}^{\prime}\left(q_{1}\right)<0$. The sign follows from the strict concavity of $\pi_{1}\left(q_{1}\right)$.
} 


$$
\frac{\partial p}{\partial l_{2}^{0}}=\frac{-n_{2} \partial q_{2} / \partial l_{2}^{0}}{n_{1}\left(d q_{1} / d p\right)+n_{2}\left(\partial q_{2} / \partial p\right)} .
$$

The numerator of the right hand side of [9] is positive because, as we showed in the last section, $\partial q_{2} / \partial l_{2}^{0}<0$. The denominator is the slope of the aggregate demand function for permits. Signing the denominator is a bit problematic because of the possibility that the permit demand of the firms that risk bankruptcy is upward sloping. However, an upward sloping aggregate demand for permits seems to us to be a very special, and probably unrealistic, case. Therefore, we ignore this possibility and assume that the aggregate demand for permits is always decreasing in the permit price, even though the financially distressed firms' demands may be increasing. Since the numerator of the right hand side of [9] is positive while the denominator is negative, $\partial p / \partial l_{2}^{0}<0$, which indicates that the equilibrium permit price is decreasing in the initial allocation of permits to financially distressed firms.

The equilibrium permit price decreases with the initial allocation of permits to financially distressed firms because they react to a higher permit allocation by reducing their demand for permits. In turn, since $d q_{1} / d p<0$, the lower permit price induces higher output by firms that do not risk bankruptcy. Holding aggregate output to $L$, then, requires that the equilibrium response of the financially insecure firms to an increase in their initial allocation of permits is that they reduce their output. To demonstrate this formally, note that $\left(\partial q_{2} / \partial p\right)\left(\partial p / \partial l_{2}^{0}\right)+\partial q_{2} / \partial l_{2}^{0}$ is the equilibrium output-response of a financially distressed firm to a change in the initial permit allocation to these firms. While we've shown that the direct effect, $\partial q_{2} / \partial l_{2}^{0}$, is less than zero, the sign of the indirect effect, $\left(\partial q_{2} / \partial p\right)\left(\partial p / \partial l_{2}^{0}\right)$, is ambiguous because the sign of $\partial q_{2} / \partial p$ is 
ambiguous. However, we can show that the total effect is negative. To do so substitute [9] into $\left(\partial q_{2} / \partial p\right)\left(\partial p / \partial l_{2}^{0}\right)+\partial q_{2} / \partial l_{2}^{0}$ to obtain

$$
\left(\partial q_{2} / \partial p\right)\left(\partial p / \partial l_{2}^{0}\right)+\partial q_{2} / \partial l_{2}^{0}=\frac{n_{2}\left(d q_{1} / d p\right)\left(\partial q_{2} / \partial l_{2}^{0}\right)}{n_{1}\left(d q_{1} / d p\right)+n_{2}\left(\partial q_{2} / \partial p\right)}<0
$$

Once again the denominator is the slope of the aggregate demand for permits, which we've assumed is negative. The numerator is positive because $d q_{1} / d p<0$ and $\partial q_{2} / \partial l_{2}^{0}<0$. Hence, the equilibrium effect of the initial allocation of permits to the firms that risk bankruptcy on their levels of production is negative.

Now let us turn to how the initial allocation of permits and bankruptcy risk affects expected industry profit at the aggregate cap on output. Using the equilibrium output levels for type 1 and type 2 firms, $q_{1}\left(p\left(L, l_{2}^{0}\right)\right)$ and $q_{2}\left(p\left(L, l_{2}^{0}\right), l_{2}^{0}\right)$, expected industry profit at an equilibrium in the permit market is

$$
\Pi=n_{1} \pi_{1}\left(q_{1}\left(p\left(L, l_{2}^{0}\right)\right)\right)+n_{2} \pi_{2}\left(q_{2}\left(p\left(L, l_{2}^{0}\right), l_{2}^{0}\right)\right) .
$$

The constraint on aggregate output implies

$$
q_{1}\left(p\left(L, l_{2}^{0}\right)\right)=\left(L-n_{2} q_{2}\left(p\left(L, l_{2}^{0}\right), l_{2}^{0}\right)\right) / n_{1} .
$$

Substitute this into [11] and differentiate with respect to $l_{2}^{0}$ to obtain

$$
\partial \Pi / \partial l_{2}^{0}=n_{2}\left(\pi_{2}^{\prime}-\pi_{1}^{\prime}\right)\left(\frac{\partial q_{2}}{\partial p} \frac{\partial p}{\partial l_{2}^{0}}+\frac{\partial q_{2}}{\partial l_{2}^{0}}\right)
$$

Recall that the firms that do not face bankruptcy choose their output so that $p=\pi_{1}^{\prime}\left(q_{1}\right)$, but that firms that do risk bankruptcy choose production so that $p>\pi_{2}^{\prime}\left(q_{2}\right)$. In a market equilibrium, therefore, $\pi_{2}^{\prime}-\pi_{1}^{\prime}<0$. The last term of [12] contains the direct and indirect price effects of changing $l_{2}^{0}$ on the output of type 2 firms, the combination of which we've just shown to be 
negative (equation [10]). Therefore, $\partial \Pi / \partial l_{2}^{0}>0$ so that expected aggregate profit when holding the industry's output to $L$ is increasing in the initial allocation of permits to firms that risk bankruptcy. Consequently, reducing the bankruptcy risk of financially insecure firms by giving them a greater initial allocation of permits increases the allocative efficiency of a tradable permit market.

\section{Concluding Remarks}

Using our results and the monotonic relationship between bankruptcy risk and the initial allocation of permits to financially insecure firms, we have generated several policy-relevant conclusions about the impact of bankruptcy risk on the performance of market-based regulations. The presence of bankruptcy risk reduces the allocative efficiency of competitive output permit markets, and makes the distribution of individual output choices dependent on the initial allocation of permits. Thus, the fundamental values of competitive tradable permit markets do not hold when some firms in the market risk bankruptcy. Financial insecurity, like market power and transaction costs, is yet another problem that can prevent markets in tradable property rights from fulfilling their theoretical promises.

However, and again like situations involving market power or transaction costs, we've demonstrated that the initial distribution of permits can be used to improve the efficiency of tradable permit markets. But we need to recognize that using the initial distribution of permits in this way would not be a trivial undertaking. There are difficulties associated with asymmetric information. A regulator must know which firms are in financial distress, which may not be readily available. Perhaps more importantly, firms would have the incentive to exaggerate their bankruptcy risk to obtain a greater allocation of permits. In addition, financially secure firms 
would very likely object to allocating more permits to insecure firms. They may even be able to argue convincingly that allocating more permits to insecure firms would basically be a subsidy for poorly performing firms. Finally, using the initial allocation to promote efficient permit markets would have to overcome the tendency to allocate permits by some sort of grandfathering rule. Those who would benefit from grandfathered permits would argue that this is a fair way to allocate permits, while ignoring the efficiency consequences of doing so.

While we have focused on the performance of tradable permit programs in this paper, our results suggest that the inefficiency associated with bankruptcy risk will also be present in other incentive-based policies, and may actually be worse. For example, policies with auctioned permits can be viewed as tradable permit programs without freely-given initial permit allocations. Since we've shown a negative relationship between the initial allocation of permits and bankruptcy risk and its associated market inefficiency, an auction, which allocates zero permits to all firms, would seem to maximize the inefficiency associated with bankruptcy risk. An output tax would produce the same result. There are good reasons to suspect that auctioning output permits or taxing output would often be more efficient than freely-allocated permits, which include their ability to produce revenue that can offset distortionary taxes in an economy, and because they may promote more rapid technologic change. However, from the singular perspective of the inefficiency caused by bankruptcy risk, the free allocation of permits to financially distressed firms may be more efficient than other incentive-based policies that do not have this feature. This issue deserves further study.

There are many other possible extensions of our model and results that are likely to be valuable. Let us mention just a few. While we have focused on a static model of permit trading, modeling bankruptcy risk in dynamic tradable permit markets (that may or may not allow some 
form of permit banking) would force us to examine the impact of financial insecurity on the efficiency of these markets over time as well as across firms. We have also assumed a fixed number of firms under a tradable property rights regulation. However, financial distress makes the endogeneity of the number of firms in an industry and the associated impacts on permit market efficiency an important area for future work. Finally, while we have assumed that firms fully comply with their output permits, allowing for noncompliance would likely yield interesting insights into the relationship between bankruptcy risk and compliance choices, and how these market difficulties work together to impact the performance of tradable permit programs.

Empirical tests of our results would be at least as important as any theoretical extension of our model. Does financial insecurity actual reduce allocative efficiency in tradable permit markets? One would hope that opportunities exist to address this question with data from real permit markets. However, in the absence of naturally occurring data, testing this hypothesis in a laboratory setting would be a straightforward exercise, and would probably lead to further insights into the relationship between the financial health of firms and the performance of tradable permit markets. 


\section{References:}

Brander, James A. and Lewis, Tracy R. 1986. “Oligopoly and Financial Structure: the Limited Liability Effect.” American Economic Review 76(5), 956-70.

Cason, Tim and Lata Gangadharan. 2003. "Transaction Costs in Tradable Permit Markets: An Experimental Study of Pollution Market Designs." Journal of Regulatory Economics 23(2), 145-165.

Damania, Richard. 2000. "Financial Structure and the Effectiveness of Pollution Control in an Oligopolistic Industry.” Resource and Energy Economics 22(1), 21-36.

Damania, Richard and Erwin H. Bulte. 2006. "Renewable Resource Regulation and Uncertain Prices: The Role of Financial Structure and Bankruptcy.” Resource and Energy Economics 28(1), 41-43.

Hahn, Robert W. 1984. “Market Power and Transferable Property Rights.” The Quarterly Journal of Economics 99(4), 753-765.

Larson, Bruce A. 1996. "Environmental Policy Based on Strict Liability: Implications of Uncertainty and Bankruptcy.” Land Economics 72(1), 33-42.

Montero, Juan-Pablo. 1998. "Marketable Pollution Permits with Uncertainty and Transaction Costs.” Resource and Energy Economics 20(1), 27-50.

Montgomery, W. David. 1972. "Markets in Licenses and Efficient Pollution Control Programs." Journal of Economic Theory 5(3), 395-418.

Spiegel, Yossef and Daniel F. Spulber. 1994. “The Capital Structure of a Regulated Firm.” RAND Journal of Economics 25(3), 424-40.

Stavins, Robert. 1995. “Transaction Costs and Tradeable Permits.” Journal of Environmental Economics and Management 29(2), 133-148.

Tietenberg, Tom H. 2006. Emissions Trading: Principles and Practice. Second edition. Resources for the Future Press, Washington. DC.

Tietenberg, Tom H. 2003. "The Tradable-Permits Approach to Protecting the Commons: Lessons for Climate Change.” Oxford Review of Economic Policy 19(3), 400-419. 